\title{
ANÁLISE DO EXTRATO HIDROALCOÓLICO DE SEMENTES DE Stryphnodendron fisSuratum Mart. (MIMOSOIDEAE) QUANTO À PRESENÇA DE METABÓLITOS SECUNDÁRIOS
}

\author{
R. P. F. SILVA, E. V. PONTUAL, J. E. S SILVA, M. M. S. SILVA
}

Universidade Federal Rural de Pernambuco, Departamento de Ciências Biológicas, Departamento de Morfologia e Fisiologia Animal.

E-mail: renattapriscilla2905@outlook.com

RESUMO: Cerca de 2,5 milhões de acidentes com serpentes peçonhentas são registrados anualmente representando um problema de saúde pública. O tratamento convencional usado nos acidentes ofídicos é a administração do soro antiofidico, que neutraliza os danos teciduais e apesar de sua alta eficiência está associado a alguns efeitos colaterais na vítima. Estudos têm mostrado que plantas com propriedades antiofidicas utilizadas por muitos trabalhadores rurais podem ser consideradas uma forma de tratamento complementar ou alternativa. Espécies de Stryphnodendron têm se destacado por em vários estudos, mostrando importantes propriedades farmacológicas, com efeitos antioxidante, cicatrizante, microbicida, antiofidico dentre outros. Stryphnodendron fissuratum, encontrada exclusivamente no Brasil e considerada tóxica para o gado, ainda possui escassas informações fitoquímicas e das propriedades biológicas do seu extrato. Assim, o presente trabalho teve como objetivos realizar o estudo fitoquímico de extrato hidroalcoólido de sementes de S. fissuratum com potencial antiofidico sobre a peçonha de Bothrops leucurus. As análises revelaram a presença de metabólitos das classes flavonoides, taninos hidrolisáveis, proantocianidinas poliméricas e pequenos traços de saponinas, os quais são reportados como potenciais agentes farmacológicos. Nesse sentido, estudos mais aprimorados deverão ser realizados para definir o extrato bruto $S$. fissuratum como um potente inibidor da ação de toxinas de serpentes do gênero Brothrops.

Palavras chave: Antiofídico, Metabólitos, Stryphnodendron, Brothrops.

ABSTRACT: About 2.5 million accidents with venomous snakes are recorded annually representing a public health problem. The conventional treatment used in ophidian accidents is the administration of antiofidic serum, which neutralizes tissue damages and although its high efficiency is associated with some side effects in the victim. Studies have shown that plants with antiofidic properties used by many rural workers can be considered a form of complementary or alternative treatment. Stryphnodendron species have been prominent in several studies, showing important pharmacological properties, with antioxidant, healing, microbicidal, antiofidic and other effects. Stryphnodendron fissuratum, found exclusively in Brazil and considered toxic to cattle, still has scarce phytochemical information and the biological properties of its extract. Thus, the present work had as objectives to carry out the phytochemical study of hydroalcoholic extract of $S$. fissuratum seeds with antifoidic potential on the venom of Bothrops leucurus. The 
analyzes revealed the presence of metabolites of the flavonoid classes, hydrolyzable tannins, polymeric proanthocyanidins and small saponins, which are reported as potential pharmacological agents. In this sense, more improved studies should be carried out to define the crude extract $S$. fissuratum as a potent inhibitor of the action of snake toxins of the genus Brothrops.

Key words: Antiofidc, Metabolites, Hydroalcoholic extract, Brothrops.

\section{INTRODUÇÃO}

O Ministério da Saúde indica que os principais acidentados com serpentes peçonhentas são trabalhadores da zona rural que exercem funções nas áreas de agronegócios. Em muitos casos por falta de informações e orientações essa parte da população utiliza de conhecimento empírico para tratar os acidentados levando muitas vezes ao aparecimento de sequelas ou ao óbito. Aqueles que procuram os postos médicos e recebem tratamento qualificado em alguns casos reagem através de uma hipersensibilidade aos componentes presentes no soro dificultado a neutralização das toxinas presentes no organismo (WEN, 2003).

Desde muitos anos os tratamentos de patologias vêm sendo realizados com princípios ativos de várias espécies vegetais minimizando em alguns casos efeitos colaterais. Sendo assim esse trabalho foi motivado a ser realizado utilizando a peçonha de uma das principais causadoras de acidentes ofídicos no Estado de Pernambuco, Bothrops leucurus, e, como agente neutralizador, o extrato bruto das sementes de Stryphnodendron fissuratum, visando a de opções alternativas de tratamentos dos acidentes ofídicos.

\section{MATERIAIS E MÉTODOS}

Para a análise fitoquímica foram utilizadas duas técnicas: a técnica de prospecção de constituintes químicos de extratos de plantas, assim denominada por MATOS, 1997 e HONDA, 1990 e Cromatografia em camada delgada (CCD) que teve seu método proposto por CHAVES et al 1997. A técnica de prospecção preliminar permitiu fazer uma abordagem do comportamento químico de extratos (MATOS, 1997). Para tanto, foram utilizados sistemas e reveladores e padrões específicos para cada classe de metabolito secundário analisado. Já a técnica de cromatografia em camada delgada, a CCD, colocamos a amostra para correr em uma base juntamente com o padrão, mergulhandose no sistema de eluição especifico. Com isso obteve-se uma solução tampão com diferentes polaridades. Essa solução foi embebendo toda placa e arrastando assim a amostra de acordo com a afinidade polar da placa fazendo com que a migração fosse determinada de acordo com a afinidade polar com a solução tampão. Com isso, conseguimos separar a amostra dependendo da polaridade. Em seguida aplicou-se o reagente de desenvolvimento especifico para cada classe de metabolito, onde só ocorreria coloração se tivéssemos o composto especifico.

\section{RESULTADOS E DISCUSSÃO}

Os produtos fitoterápicos são, algumas vezes, erroneamente considerados como seguros porque são de origem natural (GESLER, 1992). Segundo BENT \& KO, 2004, esses produtos contêm princípios bioativos capazes de causar efeitos colaterais diversos. 
De acordo com TALALAY, 2001, todo produto natural usado em finalidade terapêutica deveria ser submetido a testes de eficácia e segurança por métodos iguais aos usados por novas drogas sintéticas. Por motivos éticos, morais e legais, a obtenção de dados toxicológicos em seres humanos é bastante limitada. Com isso, as informações toxicológicas sobre compostos químicos são obtidas basicamente a partir de testes toxicológicos pré-clínicos, ou seja, com animais de laboratórios em condições previamente padronizadas (MORTON, 1998).

Logo, os resultados da análise fitoquímica das sementes do fruto de $S$. fissuratum mostraram que os principais constituintes ativos encontrados foram flavonoides, taninos hidrolisáveis, proantocianidinas poliméricas e pequenos traços de saponinas (TABELA 1). Estes são utilizadas pela população no tratamento de feridas. (MELO et al. 2007) afirmaram que as saponinas, por serem capazes de formar complexos com esteróides e fosfolipídios das membranas das células da mucosa intestinal, causam irritação na mesma. Embora estas características não tenham sido observadas em nenhum dos grupos experimentais trabalhados durante a atividade de letalidade.

Já os taninos, são compostos responsáveis pela adstringência de muitos frutos e plantas em geral, e, devido à sua complexação e a sua propriedade quelante sobre as metaloproteases presentes na peçonha de $B$. leucurus, esta se torna a base de algumas de suas propriedades biológicas, tais como o controle de insetos, fungos e bactérias (AERTS et al.,1999). Porém em algumas situações há diminuição da excreção fecal por parte de extratos que contém os taninos em sua constituição fitoquímica do, provavelmente devido ao alto peso molecular, essas moléculas estão relacionadas com a inibição da digestibilidade (MONTEIRO et al., 2005). O que não foi observado em nenhum dos nossos camundongos, pois todos mantiveram sua excreção fecal normal.

Estudos prévios realizados mostram que o extrato hidroalcoólico de S. fissuratum foi eficiente na neutralização das propriedades enzimáticas (fosfolipásica, coagulante, Serino-Proteases, proteolítica) da peçonha de Bothrops leucurus. (SILVA, 2010) considera que essas propriedades antiofídicas, de Stryphnodendron sp sejam decorrentes da presença de taninos hidrolisáveis isolados, mas que necessitam de maiores estudos acerca de seu mecanismo de ação. De acordo com PINTO et al. 2001, o efeito tóxico dos taninos, causado pela absorção intestinal dos produtos finais da hidrólise, ocasiona hemorragias, gastroenterites, necrose hepática e nefrites, entre outros.

Tabela. 1. Alguns Metabólicos secundários encontrados na avaliação fitoquímica do extrato vegetal de Stryphnodendron fissuratum. (-) ausente; $(+)$ fraco; $(++)$ médio; (+++) forte; (tr) traços (1) ; (2) proantocianidinas poliméricas

\begin{tabular}{|l|l|}
\hline Classe de metabólitos secundários & Extrato de Stryphnodendron fissuratum \\
\hline & \\
\hline Flavonoides & + \\
\hline Triterpenos & - \\
\hline Saponinas & tr \\
\hline Proantocianidinas e leucoantocianidinas & +2 \\
\hline Taninos hidrolisáveis & + \\
\hline Açúcares redutores & - \\
\hline
\end{tabular}

\section{CONCLUSÃO}

Assim, se conclui que a composição fitoquímica de Stryphnodendron fissuratum se assemelha a composição, de uma das espécies mais bem estudadas, Stryphnodendron adstringens que possui além da atividade antiofídica, propriedades anti-inflamatórias e cicatrizantes. O que nos motiva a intensificar a investigações acerca dessa espécie vegetal e suas propriedades farmacológicas. 
Sendo assim, daremos continuidade ao estudo da neutralização das atividades biológicas resultantes do envenenamento por esta peçonha em presença do extrato vegetal bruto de S. fissuratum e avaliaremos a utilização desse vegetal com fins terapêuticos como uma sugestiva opção para trabalhos futuros que visem o encontro de nova atividade farmacológica.

\section{REFERÊNCIAS}

AERTS, T.J.; BARRY, T.N.; MCNABB, W.C. Polyphenols and agriculture: beneficial effects of proanthocyanodins in forages. Agriculture, Ecosystems and Environments, v.75, p.1-12, 1999.

BENT, S.; KO, R. Commonly used herbal medicines in the United States: a review. The American Journal of Medicine, v.116, p.478-85, 2004.

CHAVES, M.H, Análise de extratos de plantas por Cromatografia em Camada Delgada: metodologia aplicada à disciplina "Química Orgânica". Química Nova, 20(5), 1997.

GESLER, W.M. Therapeutic landscapes: medical issue in light of the new cultural geography. Social Sience and medicine, v.34, p.735-46, 1992.

HONDA, N. K. et. al. Estudo químico de plantas de Mato Grosso do Sul I: triagem fitoquímica. Campo Grande - MS, EUFMS, 1990.

MATOS, F. J. A. Introdução à Fitoquímica Experimental. 2 ed. Fortaleza: Edições UFC, 1997.

MELO, D.S. et al. Efeitos da farinha de folhas de mandioca sobre a peroxidação lipídica, o perfil lipídico sanguíneo e o peso do fígado de ratos. Ciência e Agrotecnologia, v.31, n.2, p.420-8, 2007.

MONTEIRO, J.M.; ALBUQUERQUE, U. O.; ARAÚJO, E.L. Taninos: uma abordagem da química a ecologia. Química Nova, v. 28, n. 5, p. 892-896, 2005.

MORTON, D.M. Importance of species selection in drugtocicity testing. Toxicology Letters, v.102, p.545-50, 1998.

PINTO, L.G.Q. et al. Desempenho do piauçu (Leporinus macrocephalus) arraçoado em dietas contendo diferentes teores de tanino. Revista Brasileira Zootecnia, v.30, n.4, p.1164-71, 2001 .

Silva, N.L.A., Miranda, F.A.A., Conceição, G.M., 2010. Triagem fitoquímica de plantas do cerrado, da área de proteção ambiental do Inhamun, Caxias, Maranhão. Scientia Plena 6.

TALALAY, P. The importance of using scientific principles in the development of medicinal agentes from plants. Academic Medicine, v.76, p.238-47, 2001.

WEN, F.H. Soroterapia. In: Cardoso, J.L.C (Coord.) Animais peçonhentos no Brasil: biologia, clínica e terapêutica dos acidentes. São Paulo: Sarvier, 2003. p.p. 381. 